\title{
A meta-analysis of clinical trials assessing the effect of radiofrequency ablation for breast cancer
}

This article was published in the following Dove Press journal:

OncoTargets and Therapy

23 March 2016

Number of times this article has been viewed

\author{
Jiayan Chen ${ }^{1, *}$ \\ Chi Zhang ${ }^{1, *}$ \\ Fei $\mathrm{Li}^{1, *}$ \\ Liping $X u^{\prime}$ \\ Hongcheng Zhu' \\ Shui Wang ${ }^{2}$ \\ Xiaoan Liu² \\ Xiaoming Zha ${ }^{2}$ \\ Qiang Ding ${ }^{2}$ \\ Lijun Ling ${ }^{2}$ \\ Wenbin Zhou ${ }^{2}$ \\ Xinchen Sun' \\ 'Department of Radiation Oncology, \\ ${ }^{2}$ Department of Breast Surgery, \\ The First Affiliated Hospital, \\ Nanjing Medical University, Nanjing, \\ People's Republic of China \\ *These authors contributed equally \\ to this work
}

Correspondence: Xinchen Sun

Department of Radiation Oncology,

The First Affiliated Hospital, Nanjing

Medical University, 300 Guangzhou Road,

Nanjing, People's Republic of China

Tel +8625682I 7677

Email sunxinchen2008@126.com
Background: Radiofrequency ablation (RFA) is a minimally invasive thermal ablation technique. We conducted a meta-analysis based on eligible studies to assess the efficacy and safety of RFA for treating patients with breast cancer.

Methods: A literature search was conducted in PubMed, Embase, and Web of Science databases. Eligible studies were clinical trials that assessed RFA in patients with breast cancer. The outcomes included complete ablation rate, recurrence rate, excellent or good cosmetic rates, and complication rate. A random-effects or fixed-effects model was used to pool the estimate, according to the heterogeneity among the included studies.

Results: Fifteen studies, with a total of 404 patients, were included in this meta-analysis. Pooled results showed that $89 \%$ (95\% confidence interval: $85 \%-93 \%$ ) of patients achieved a complete ablation after RFA treatment and $96 \%$ of patients reported a good-to-excellent cosmetic result. Although the pooled result for recurrence rate was 0 , several cases of relapse were observed at different follow-up times. No RFA-related complications were recorded, except for skin burn with an incidence of $4 \%$ (95\% confidence interval: $1 \%-6 \%)$.

Conclusion: This meta-analysis showed that RFA can be a promising alternative option for treating breast cancer since it produces a higher complete ablation rate with a low complication rate. Further well-designed randomized controlled trials are needed to confirm the efficacy and safety of RFA for breast cancer.

Keywords: radiofrequency ablation, breast cancer, meta-analysis

\section{Introduction}

The treatment for early breast cancer has evolved over the past decade. Nowadays, there is an increasing demand for minimally invasive treatments for small breast cancer. Breast conservation therapy has largely replaced mastectomy for the surgical treatment of earlystage breast cancer, as several randomized trials have shown a similar survival outcome between them. ${ }^{1-3}$ Moreover, sentinel lymph node biopsy has been widely accepted as an effective method for evaluating axillary nodal status for node-negative breast cancer, which avoids unnecessary axillary lymph node dissection. ${ }^{4,5}$ Owing to these fundamental changes in the breast cancer treatment strategy, there is an impetus to replace the less-invasive surgery with ablation techniques in the treatment of primary tumor without surgery.

Several minimally invasive ablation techniques have been applied for the treatment of small breast cancer, including cryosurgery, laser ablation, and thermoablation. Among them, radiofrequency ablation (RFA) is one of the most promising techniques. The treatment efficacy of RFA has been investigated in several studies, and results showed that RFA would be most effective for the treatment of tumors $<3 \mathrm{~cm}^{6-8}$ The purpose of this meta-analysis is to assess the feasibility and safety of RFA in the treatment of patients with breast cancer. 


\section{Materials and methods}

\section{Literature search}

We conducted a comprehensive literature search in PubMed, Embase, and Web of Science databases from their inception through August 18, 2015. The following search terms were used: ("breast neoplasms"[MeSH Terms]) OR ("breast"[All Fields] AND "neoplasms"[All Fields]) OR ("breast neoplasms"[All Fields]) OR ("breast"[All Fields] AND “cancer"[All Fields]) OR ("breast cancer"[All Fields]) AND (radiofrequency [All Fields] AND ablation [All Fields]). The search was limited to human subjects, and no language restriction was imposed. We also manually searched the reference lists of included trials and reviews until no potential eligible trials could be found.

\section{Review strategy}

We used Endnote bibliographic software to build up an electronic library of citations identified in the literature searches. PubMed, Embase, and Web of Science databases were searched using Endnote, and duplicate records were deleted. Two independent investigators ( $\mathrm{CJ}$ and $\mathrm{ZC}$ ) were trained to perform the abstract/title review and then full-text review. Discrepancies between the investigators were resolved by consensus and discussion.

\section{Study inclusion and exclusion criteria}

All clinical trials assessing the efficacy and safety of RFA as a minimally invasive strategy for breast cancers were considered eligible for analysis. The following inclusive selection criteria were applied: 1) study population: adult women older than 18 years and had mammographic or ultrasonographic or magnetic resonance imaging evidence of breast cancer; 2) intervention: RFA; and 3) outcome measure: complete ablation rate and complication. Review articles, abstracts, editorials, case reports, and letters were not included in this meta-analysis.

\section{Data extraction}

Two independent investors (CJ and LF) extracted the following data from the included studies: first author, year of publication, number of patients, baseline character of patients, complete ablation rate, recurrence rate, excellent or good cosmetic rate, and incidence of complications. A standardized Excel file (Microsoft Corporation, Redmond, WA, USA) was established to extract the data from each study. When several publications from the same trial appeared, we included only the most informative article or the latest study to avoid duplication of information.

\section{Statistical analysis}

Before the data were pooled, we tested the heterogeneity among the studies using $I^{2}$ statistics. ${ }^{9}$ The studies were considered to have low, moderate, or high heterogeneity when the value of $I^{2}$ was $25 \%-50 \%, 50 \%-75 \%$, or $>75 \%$, respectively. ${ }^{10}$ A value of $I^{2}>50 \%$ indicates significant heterogeneity. ${ }^{11}$ When heterogeneity was found among the included studies, a random-effect model was used to pool the estimates; ${ }^{12}$ otherwise, a fixed-effect model was applied. ${ }^{13}$ Publication bias was evaluated using the test proposed by Begg and Mazumdar. ${ }^{14} \mathrm{~A} P$-value of $<0.05$ was considered statistically significant. All analyses were performed using STATA Version 12.0 (StataCorp LP, College Station, TX, USA).

\section{Results}

\section{Study identification and selection}

The initial search yielded 1,678 records, of which 976 were excluded for the duplicate studies and 656 studies were excluded after a review of title/abstract, and the remaining 46 potential studies were included for the full-text review. Of the 46 studies for final analysis, 31 were excluded for the following reasons: 18 were unrelated with our topics, five were animal experiment, three did not provide outcomes of interest, and five used other ablation rather than RFA method. Thus, 15 studies $^{15-29}$ met the inclusion criteria, and they were included in this meta-analysis (Figure 1).

\section{Characteristics of eligible studies}

The baseline characteristics of the included studies are presented in Table 1. These studies were published between 2001 and 2012. The sample sizes in these studies ranged from 10 to 52 (total of 404). The age of the patients ranged from 33 to 89 years, with a mean age $>50$ years. Of the 15 studies, eight studies reported that the tumor size was $<2 \mathrm{~cm}$, five studies reported $<3 \mathrm{~cm}$, and the remaining two studies reported $<5 \mathrm{~cm}$. The greatest tumor size was $5 \mathrm{~cm}$, which was reported by Tsuda et al. ${ }^{29}$ Among these studies that presented the tumor histology, invasive ductal carcinoma was the primary type of carcinoma, which accounted for $74.7 \%$. All the studies used ultrasound as image guidance to perform RFA. The mean temperature and time for tumor ablation were $95^{\circ} \mathrm{C}$ and 15 minutes, except for the method used by Wiksell et al, ${ }^{18}$ in which the tissue temperature and time were applied at $85^{\circ} \mathrm{C}$ and 10 minutes.

\section{Complete ablation rate}

Eleven studies reported the data of complete ablation rate. ${ }^{15-18,21-25,28,29}$ The complete ablation rate among these 


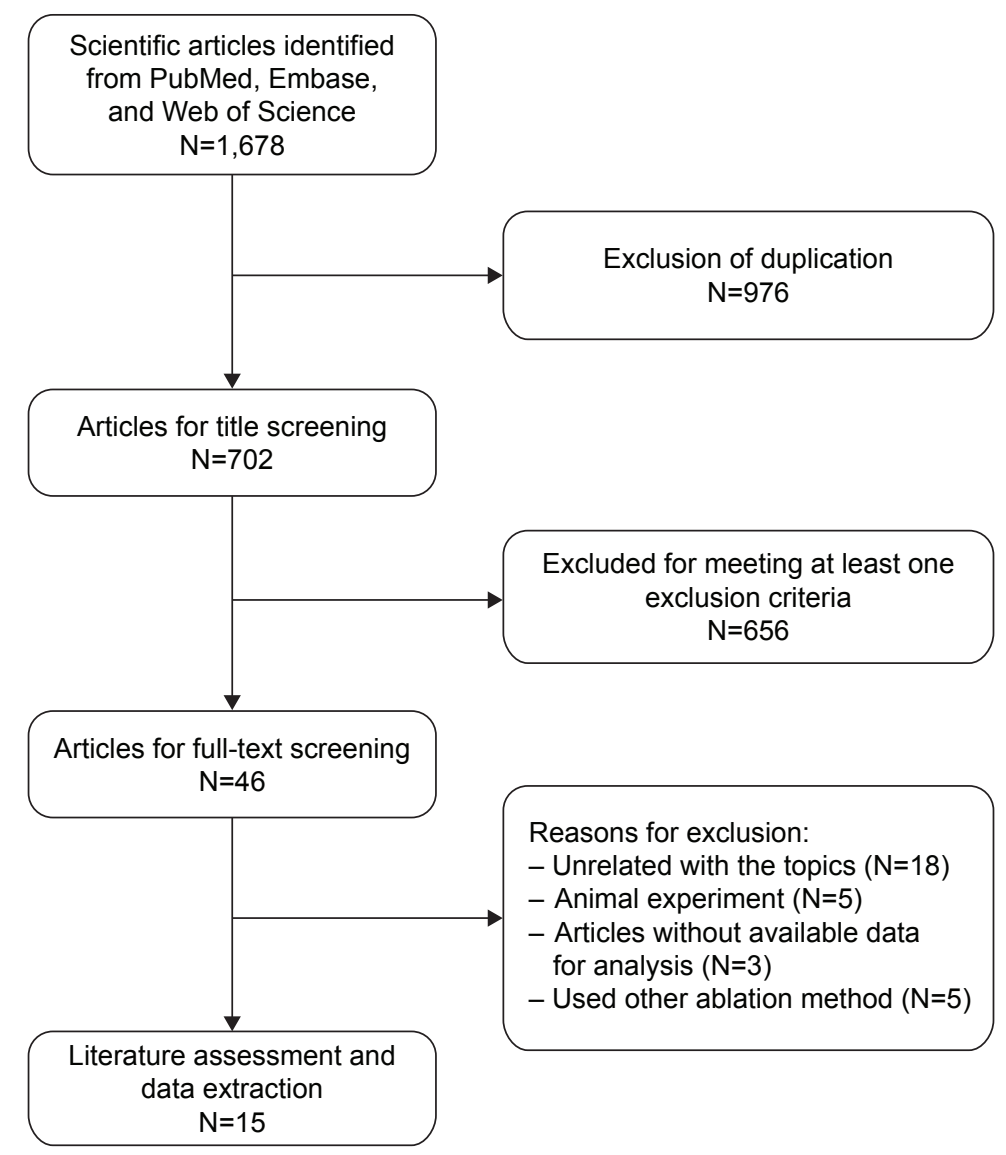

Figure I Search strategy and flowchart for the meta-analysis.

studies ranged from $76 \%$ to $96.15 \%$. Pooled estimates suggested that among the patients receiving RFA, 89\% (95\% confidence interval [CI]: 85\%-93\%) achieved a complete ablation (Figure 2). No heterogeneity was identified across these included studies $\left(I^{2}=0.0 \%, P=0.454\right)$.

\section{Excellent cosmetic and good cosmetic}

Four studies provided the data of cosmetic results. ${ }^{19,23,26,27}$ The cosmetic was scored according to the Radiation Therapy Oncology Group cosmesis scoring criteria. The aggregated results of these studies suggested that, of the patients treated

Table I Baseline characteristics of patients in the trials included in the meta-analysis

\begin{tabular}{|c|c|c|c|c|c|}
\hline Study & Number & $\begin{array}{l}\text { Mean age } \\
\text { (range, years) }\end{array}$ & $\begin{array}{l}\text { Tumor size } \\
(\mathrm{cm})\end{array}$ & Tumor histology & $\begin{array}{l}\text { Follow-up } \\
\text { (months) }\end{array}$ \\
\hline Hayashi et al ${ }^{15}$ & 22 & $73(60-80)$ & $\leq 1.0$ & NR & NR \\
\hline Noguchi et al ${ }^{16}$ & 10 & $54(33-70)$ & $<2.0$ & Invasive ductal/intraductal carcinoma: $7 / 3$ & NR \\
\hline Izzo et $\mathrm{al}^{17}$ & 26 & $57(37-78)$ & $1.8(0.7-3.0)$ & Infiltrating ductal/lobular/tubular: I7/6/3 & NR \\
\hline Wiksell et al ${ }^{18}$ & 33 & NR $(46-83)$ & $0.6-1.5$ & Ductal/lobular/mucinous/tubular: 26/2/I/4 & $55 \pm 21$ \\
\hline Wilson et al $^{19}$ & 40 & $68.8 \pm 10.9$ & $0.2-2.6$ & NR & $1-60$ \\
\hline Palussière et $\mathrm{al}^{20}$ & 21 & $79(70-88)$ & $<3.0$ & Invasive ductal/lobular/mucinous carcinoma: I7/3/I & $49.6(17-77)$ \\
\hline Burak et $\mathrm{al}^{2 !}$ & 10 & $53.7(37-67)$ & $1.15(0.8-1.5)$ & NR & NR \\
\hline Ohtani et $\mathrm{al}^{22}$ & 41 & $59(38-92)$ & $<2.0$ & Invasive ductal/noninvasive ductal carcinoma: $36 / 5$ & NR \\
\hline Medina-Franco et $\mathrm{al}^{23}$ & 25 & $55.3(42-89)$ & $2.08(0.9-3.8)$ & Infiltrating ductal/lobular/mixed carcinoma: $2 \mid / 2 / 2$ & $1-6$ \\
\hline Fornage et $\mathrm{al}^{24}$ & 21 & $56(38-80)$ & $<2.0$ & Invasive ductal/lobular carcinoma: $19 / 2$ & NR \\
\hline Earashi et $\mathrm{al}^{25}$ & 17 & $55(33-78)$ & I.I $(0.5-2.4)$ & Invasive ductal/noninvasive ductal carcinoma: $21 / 3$ & $1-6$ \\
\hline Oura et $\mathrm{al}^{26}$ & 52 & $55(37-83)$ & $1.3(0.5-2.0)$ & Ductal/invasive ductal/lobular/tubular: 7/42/2/I & Every 2-3 \\
\hline Yamamoto et $\mathrm{al}^{27}$ & 29 & $55.9(38-78)$ & $1.28(0.5-1.9)$ & NR & $17(2-4 \mid)$ \\
\hline Seki et $\mathrm{al}^{28}$ & 15 & $61(36-82)$ & $1.7(0.5-3.0)$ & Invasive ductal carcinoma: 15 & 18 \\
\hline Tsuda et $\mathrm{a}^{29}$ & 28 & $36-82$ & $2.21(0.6-5.0)$ & Intraductal carcinoma: 28 & NR \\
\hline
\end{tabular}

Abbreviation: NR, not reported. 


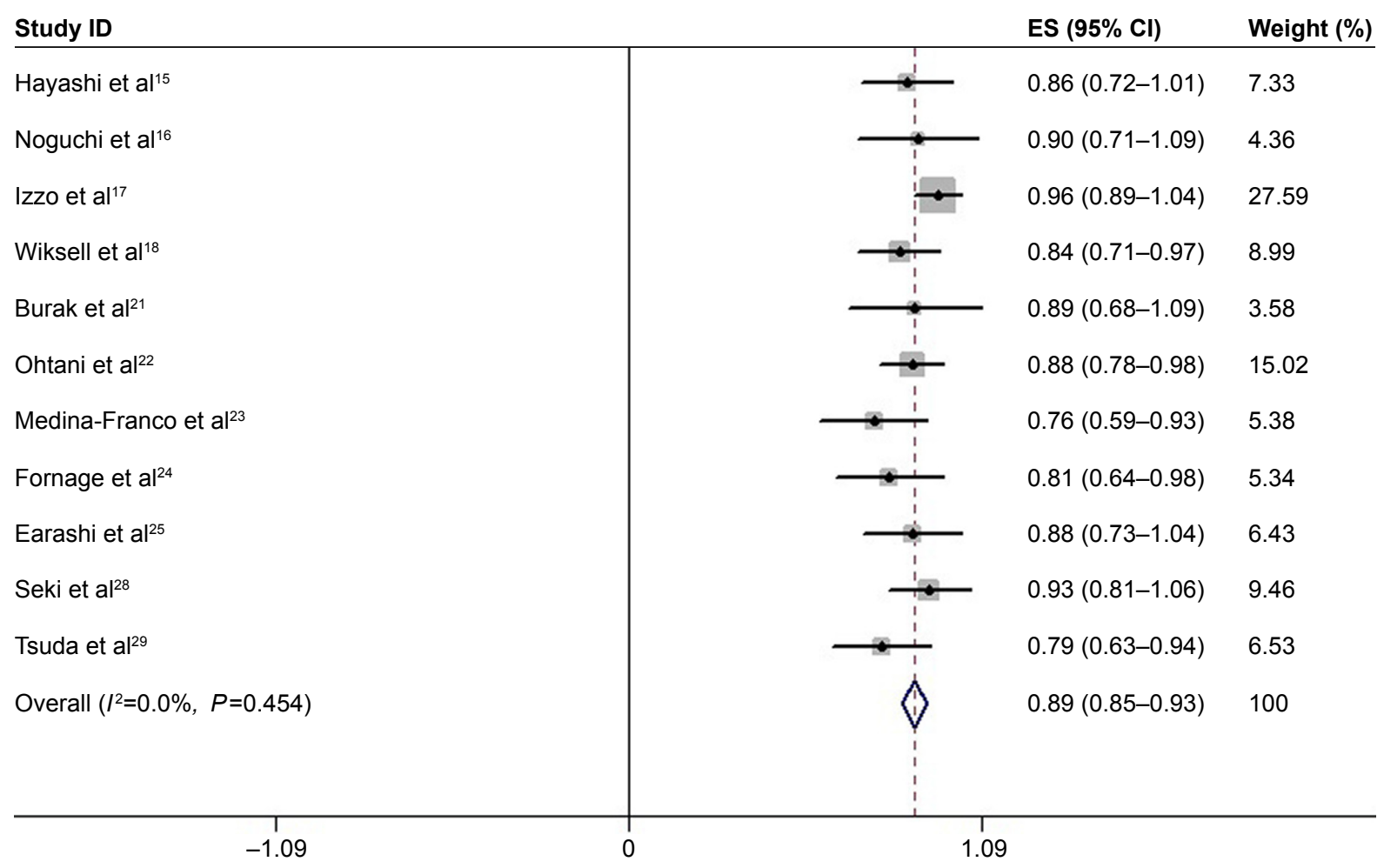

Figure 2 Forest plot showing the complete ablation rate of radiofrequency ablation in the treatment of patients with breast cancer. Abbreviations: $\mathrm{Cl}$, confidence interval; $\mathrm{ES}$, estimates.

with RFA, 77\% (95\% CI: 57\%-97\%) rated their cosmetic result as excellent and 19\% (95\% $\mathrm{CI}$ : 4\%-34\%) rated as good (Figure 3). Overall, 96\% of patients reported a goodto-excellent cosmetic result.

\section{Recurrence rate}

Five studies presented the data of recurrent rate. ${ }^{19,20,25-27} \mathrm{Of}$ them, three ${ }^{25-27}$ reported that no recurrence occurred at the final follow-up. The follow-up of these studies was 1-7, 6-30, and 2-41 months, respectively. Whereas, in another study, ${ }^{20}$ one of the 21 patients reported a local relapse at the 1-year follow-up, and three additional patients presented with cancer recurrence outside the ablation zone at 30,48, and 60 months. Moreover, the remaining study reported that one $(1.3 \%)$ of 73 patients developed a true in-site recurrence at the $55 \pm 21$ months follow-up. ${ }^{19}$ The pooled results indicated that patients treated with RFA had no local recurrence at a maximum follow-up of 76 months (Figure 4).

\section{Complications}

Seven studies reported the complications. ${ }^{15,17,20,22,23,26,27}$ No RFA-related complications were recorded by them. However, skin burn was noticed among these studies. Pooled estimates showed that the incidence of skin burn was 4\% (95\% CI: 1\%-6\%; Figure 5). And there was no significant heterogeneity among the studies $\left(I^{2}=18.9 \%\right.$, $P=0.286)$.

\section{Publication bias}

The test proposed by Begg and Mazumdar ${ }^{14}$ was used to evaluate publication bias, and the result revealed that no potential publication bias existed among the included studies $(Z=0.78, P=0.436)$.

\section{Discussion}

This study was a meta-analysis with the objective of assessing the efficacy and safety of RFA in the treatment of breast cancer. Our study indicated that among the patients with breast cancer who underwent RFA, 89\% achieved a complete ablation, 96\% reported a good-to-excellent cosmetic result, and 4\% developed skin burn. This study indicated RFA is promising as a minimally invasive ablation technique in the local treatment of breast cancer.

RFA is a thermal ablation technique that has been applied for benign and malignant tumors. ${ }^{30,31}$ RFA causes local tumor cell death by thermal coagulation and protein denaturation. ${ }^{21,32,33}$ High-frequency alternating current flows from the tip of the electrode into the surrounding tissue causing ions to oscillate back and forth, thus generating frictional heat. ${ }^{34,35}$ Cell death approximately occurs $>45^{\circ} \mathrm{C}-50^{\circ} \mathrm{C} .{ }^{36}$ The targeted 


\begin{tabular}{|c|c|c|c|}
\hline Study ID & & ES $(95 \% \mathrm{Cl})$ & Weight (\%) \\
\hline Excellent cosmetic & & & \\
\hline Wilson et $\mathrm{al}^{19}$ & $\longrightarrow$ & $0.45(0.30-0.60)$ & 23.73 \\
\hline Medina-Franco et $\mathrm{al}^{23}$ & & $0.80(0.64-0.96)$ & 23.61 \\
\hline Oura et $\mathrm{a}^{26}$ & $\rightarrow$ & $0.83(0.72-0.93)$ & 25.79 \\
\hline Yamamoto et $\mathrm{al}^{27}$ & $\rightarrow$ & $0.97(0.90-1.03)$ & 26.88 \\
\hline Subtotal $\left(I^{2}=92.1 \%, P=0.000\right)$ & & $0.77(0.57-0.97)$ & 100 \\
\hline Good cosmetic & & & \\
\hline Wilson et $\mathrm{al}^{19}$ & $\longrightarrow$ & $0.45(0.30-0.60)$ & 22.66 \\
\hline Medina-Franco et $\mathrm{al}^{23}$ & $\longrightarrow$ & $0.20(0.04-0.36)$ & 22.48 \\
\hline Oura et $a^{26}$ & $\rightarrow$ & $0.12(0.03-0.20)$ & 26.92 \\
\hline Yamamoto et $\mathrm{al}^{27}$ & $\star$ & $0.03(-0.03-0.10)$ & 27.94 \\
\hline Subtotal $\left(I^{2}=88.0 \%, P=0.000\right)$ & & $0.19(0.04-0.34)$ & 100 \\
\hline
\end{tabular}

Figure 3 Forest plot showing the good or excellent cosmetic rate of radiofrequency ablation in the treatment of patients with breast cancer.

Note: Weights are from random-effects analysis.

Abbreviations: $\mathrm{Cl}$, confidence interval; ES, estimates.

temperature mostly used at the tip of prongs was $95^{\circ} \mathrm{C}$ and lasted for 15 minutes. ${ }^{15,24}$ This setting could melt the fatty tissue and also lead to bad cosmetic results. However, the lesions would achieve an equal ablation effect when RFA was set at a lower target temperature and a shorter ablation time. ${ }^{24}$
In this meta-analysis, we found that the complete ablation rate was $89 \%$, indicating a high rate of complete tumor ablation for patients receiving RFA. The complete ablation rate among these studies ranged from $76 \%$ to $96.15 \%$. The highest complete ablation rate was observed in the study

\begin{tabular}{|c|c|c|}
\hline Study ID & ES $(95 \% \mathrm{Cl})$ & Weight (\%) \\
\hline Yamamoto et $\mathrm{al}^{27}$ & $0.00(-0.00-0.00)$ & 15.85 \\
\hline Oura et $\mathrm{al}^{26}$ & $0.00(-0.00-0.00)$ & 63.41 \\
\hline Earashi et $\mathrm{al}^{25}$ & $0.00(-0.00-0.00)$ & 20.73 \\
\hline Palussière et $\mathrm{al}^{20}$ & $0.05(-0.04-0.14)$ & 0.00 \\
\hline Palussière et $\mathrm{al}^{20}$ & $0.14(-0.01-0.29)$ & 0.00 \\
\hline Wilson et $\mathrm{al}^{19}$ & $0.01(-0.01-0.04)$ & 0.00 \\
\hline Overall $\left(I^{2}=10.1 \%, P=0.351\right)$ & $0.00(-0.00-0.00)$ & 100 \\
\hline
\end{tabular}

Figure 4 Forest plot showing the recurrence rate of radiofrequency ablation in the treatment of patients with breast cancer. Abbreviations: $\mathrm{Cl}$, confidence interval; ES, estimates. 


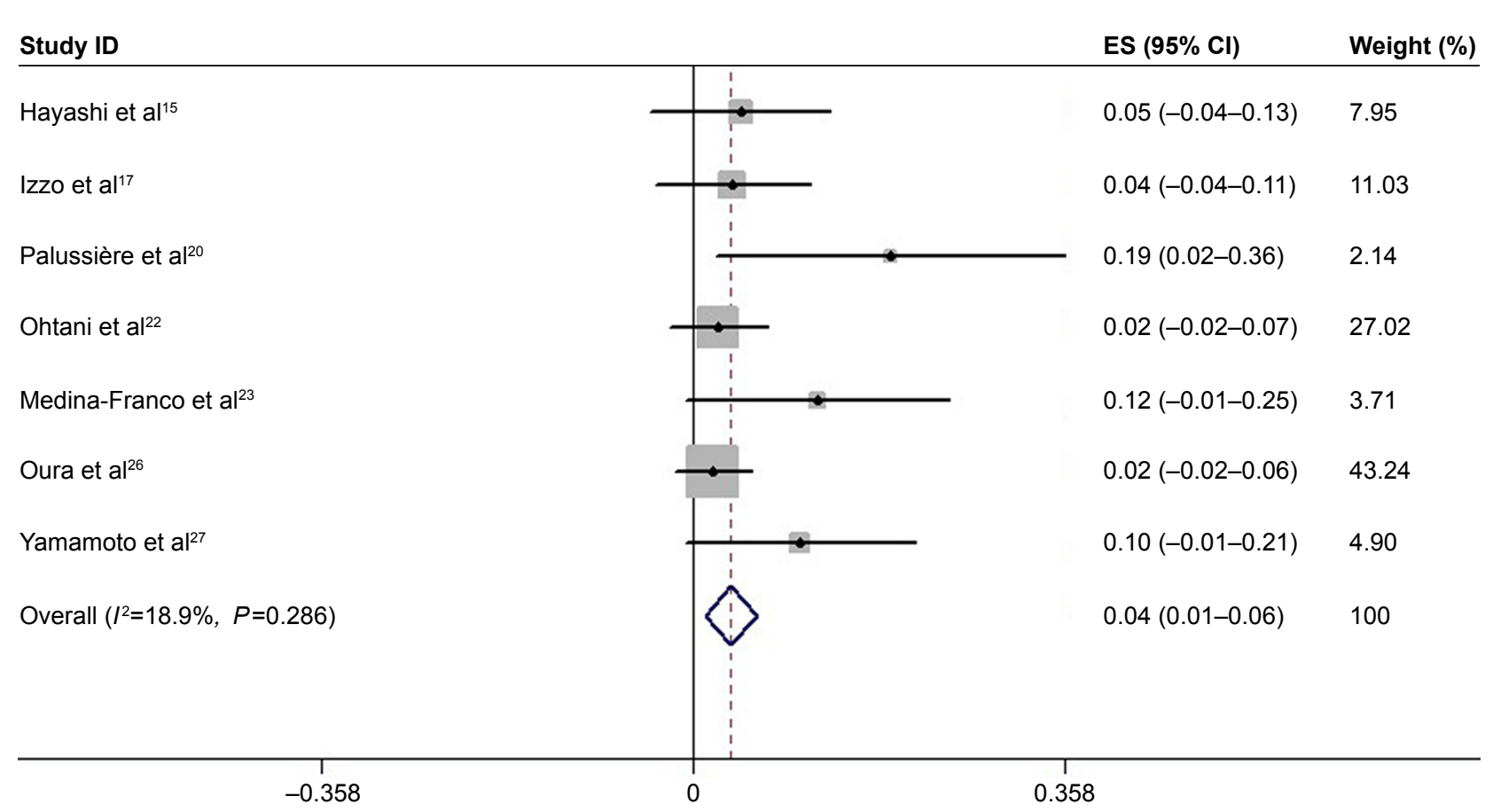

Figure 5 Forest plot showing the complication rate of radiofrequency ablation in the treatment of patients with breast cancer. Abbreviations: $\mathrm{Cl}$, confidence interval; $\mathrm{ES}$, estimates.

conducted by Izzo et al, ${ }^{17}$ in which ultrasound-guided RFA was performed in 26 patients with $\mathrm{T} 1$ and $\mathrm{T} 2$ breast tumors and then followed by immediate resection. Among these patients, 25 (96.15\%) achieved a complete coagulation necrosis of tumor, while the remaining one had a microscopic focus of viable tissue adjacent to the needle shaft site. ${ }^{17}$ Another study performed RFA to treat patients with invasive breast carcinomas; however, the complete ablation rate was only $76 \%{ }^{23}$ In that study, the authors restricted patients to those with invasive breast cancers, no multicentric tumors, and no previous chemotherapy. Under ultrasound guidance, salinecooled RFA was performed on tumors and a 5-mm margin of surrounding breast tissue, and then surgical resection was followed. ${ }^{23}$ Of the 25 patients, only 19 (76\%) patients showed no evidence of viable malignant cells by the pathologic analysis of NDPH stain. ${ }^{23}$ The complete ablation rate for tumors $<2 \mathrm{~cm}(92.8 \%)$ was significantly higher than that of tumors $>2 \mathrm{~cm}(54.5 \%)$.

Regarding the recurrence, several studies revealed that no patients developed breast recurrence at their final follow-up, while the remaining studies reported a recurrence rate ranging from $1.37 \%$ to $14.29 \%$. In the trial conducted by Oura et al, ${ }^{26} 52$ patients with breast cancer received one session of RFA, for a maximum time of 30 minutes for the first 29 patients and 15 minutes for the following 23 patients. And the authors reported that no recurrence developed at the average follow-up of 15 months (6-30 months) after RFA. ${ }^{26}$ Similarly, in another trial conducted by Yamamoto et al, ${ }^{27}$ none of the 29 patients who underwent RFA recurred after a median follow-up of 17 months (2-41 months). ${ }^{27}$ However, in the trial conducted by Palussière et $\mathrm{al},{ }^{20}$ four patients developed cancer recurrence after RFA treatment. In that study, patients were all older than 70 years ( $70-88$ years) and had undergone neoadjuvant endocrine therapy within the past 6 months. The tumor size was $<3 \mathrm{~cm}$, and three patients were diagnosed with lobular carcinoma. During the 9-month follow-up, one patient was presented with a local relapse, and three additional patients developed cancer recurrence outside the ablation zone at 30, 48, and 60 months, two of whom were lobular carcinoma. ${ }^{20}$ Then, the authors suggest that RFA should not be recommended for lobular carcinoma.

With advances in diagnostic modalities, such as mammography, ultrasonography, and magnetic resonance imaging, the breast tumors with a diameter of $<1 \mathrm{~cm}$ could be detected. Therefore, surgical treatment for breast cancer has become less invasive. However, the cosmetic problems still remain. In this study, we found that $96 \%$ of patients who underwent RFA reported a good-to-excellent cosmetic result. The result of RFA was higher than those of external beam radiation and partial breast irradiation, in which the rate of excellent-to-good cosmetic results ranged from $77.6 \%$ to $83.3 \%{ }^{37,38}$ 
In terms of complications of RFA, there were seven studies reporting no RFA-related complications except for skin burn. Skin burn is the common complication of RFA in the treatment of breast cancer. The skin or underlying muscle close to the tumor is of concern because RFA can result in skin necrosis or chest wall burn. In the study conducted by Palussière et al, ${ }^{20}$ four of the 21 patients developed skin burn, which finally showed spontaneous healing after a maximum of 2 months. In another study conducted by Medina-Franco et al, ${ }^{23}$ in three of the 25 patients (12\%) superficial skin burns occurred that required local excision. The authors pointed that there was no acute skin necrosis; however, they performed the surgical excision immediately after RFA treatment. ${ }^{23}$ Thus, the skin necrosis may not be well assessed since a delay in time period between RFA and resection would be necessary.

Although this meta-analysis indicated that RFA produced a higher complete ablation rate with a low complication rate, there are several problems that remain to be resolved: 1) lack of ability to precisely determine tumor size, 2) determination of $100 \%$ tumor cell killing, 3 ) ability to follow local recurrence, and 4) cosmetic outcome. ${ }^{39}$ Further studies are needed to determine whether the use of RFA for small breast cancer can provide local control and survival rates equivalent to those of conventional breast conservative surgery.

There are some potential limitations in this meta-analysis that should be considered. First, our study was conducted on 15 trials, and most of them had relatively small sample size. Compared with larger trials, small trials are more likely to result in overestimates of the treatment effect. Thus, our conclusion should be interpreted with caution. Second, there were variations in patients' characteristics among the included studies, including breast size, tumor location, composition of the breast tissue (fat content), and vascularity of the breast. These factors may increase the heterogeneity and have a potential on the pooled results.

\section{Conclusion}

In conclusion, this meta-analysis showed that RFA can be a promising alternative option for invasive breast cancer since it produces a higher complete ablation rate with a low complication rate. However, considering that this study was conducted on small and nonrandomized controlled trials, the efficacy and safety of RFA for breast cancer should be confirmed with large-scale, well-performed trials.

\section{Disclosure}

The authors report no conflicts of interest in this work.

\section{References}

1. Fisher B, Redmond C, Poisson R, et al. Eight-year results of a randomized clinical trial comparing total mastectomy and lumpectomy with or without irradiation in the treatment of breast cancer. N Engl J Med. 1989;320(13):822-828.

2. Jacobson JA, Danforth DN, Cowan KH, et al. Ten-year results of a comparison of conservation with mastectomy in the treatment of stage I and II breast cancer. N Engl J Med. 1995;332(14):907-911.

3. Veronesi U, Salvadori B, Luini A, et al. Conservative treatment of early breast cancer. Long-term results of 1232 cases treated with quadrantectomy, axillary dissection, and radiotherapy. Ann Surg. 1990;211(3):250-259.

4. Giuliano AE, Jones RC, Brennan M, Statman R. Sentinel lymphadenectomy in breast cancer. J Clin Oncol. 1997;15(6):2345-2350.

5. Effects of radiotherapy and surgery in early breast cancer. An overview of the randomized trials. Early Breast Cancer Trialists' Collaborative Group. N Engl J Med. 1995;333(22):1444-1455.

6. Singletary SE. New approaches to surgery for breast cancer. Endocr Relat Cancer. 2001;8(4):265-286.

7. Jeffrey SS, Birdwell RL, Ikeda DM, et al. Radiofrequency ablation of breast cancer: first report of an emerging technology. Arch Surg. 1999; 134(10):1064-1068.

8. Noguchi M. Radiofrequency ablation treatment for breast cancer to meet the next challenge: how to treat primary breast tumor without surgery. Breast Cancer. 2003;10(1):1-3.

9. Cochran W. The combination of estimates from different experiments. Biometrics. 1954;10:101-129.

10. Higgins JP, Thompson SG, Deeks JJ, Altman DG. Measuring inconsistency in meta-analyses. BMJ. 2003;327(7414):557-560.

11. Armitage P, Berry G, Matthews J. Analysing means and proportions. Statistical Methods in Medical Research. Oxford: Blackwell Science. 2002:83-146.

12. DerSimonian R, Laird N. Meta-analysis in clinical trials. Control Clin Trials. 1986;7(3):177-188.

13. Mantel N, Haenszel W. Statistical aspects of the analysis of data from retrospective studies of disease. J Natl Cancer Inst. 1959;22(4): 719-748.

14. Begg CB, Mazumdar M. Operating characteristics of a rank correlation test for publication bias. Biometrics. 1994;50(4):1088-1101.

15. Hayashi AH, Silver SF, van der Westhuizen NG, et al. Treatment of invasive breast carcinoma with ultrasound-guided radiofrequency ablation. Am J Surg. 2003;185(5):429-435.

16. Noguchi M, Earashi M, Fujii H, Yokoyama K, Harada K, Tsuneyama K. Radiofrequency ablation of small breast cancer followed by surgical resection. J Surg Oncol. 2006;93(2):120-128.

17. Izzo F, Thomas R, Delrio P, et al. Radiofrequency ablation in patients with primary breast carcinoma: a pilot study in 26 patients. Cancer. 2001;92(8):2036-2044.

18. Wiksell H, Lofgren L, Schassburger KU, et al. Feasibility study on the treatment of small breast carcinoma using percutaneous US-guided preferential radiofrequency ablation (PRFA). Breast. 2010;19(3): 219-225.

19. Wilson M, Korourian S, Boneti C, et al. Long-term results of excision followed by radiofrequency ablation as the sole means of local therapy for breast cancer. Ann Surg Oncol. 2012;19(10):3192-3198.

20. Palussière J, Henriques C, Mauriac L, et al. Radiofrequency ablation as a substitute for surgery in elderly patients with nonresected breast cancer: pilot study with long-term outcomes. Radiology. 2012; 264(2):597-605.

21. Burak WE Jr, Agnese DM, Povoski SP, et al. Radiofrequency ablation of invasive breast carcinoma followed by delayed surgical excision. Cancer. 2003;98(7):1369-1376.

22. Ohtani S, Kochi M, Ito M, et al. Radiofrequency ablation of early breast cancer followed by delayed surgical resection - a promising alternative to breast-conserving surgery. Breast. 2011;20(5):431-436. 
23. Medina-Franco H, Soto-Germes S, Ulloa-Gomez JL, et al. Radiofrequency ablation of invasive breast carcinomas: a phase II trial. Ann Surg Oncol. 2008;15(6):1689-1695.

24. Fornage BD, Sneige N, Ross MI, et al. Small $(<$ or $=2-\mathrm{cm})$ breast cancer treated with US-guided radiofrequency ablation: feasibility study. Radiology. 2004;231(1):215-224.

25. Earashi M, Noguchi M, Motoyoshi A, Fujii H. Radiofrequency ablation therapy for small breast cancer followed by immediate surgical resection or delayed mammotome excision. Breast Cancer. 2007;14(1):39-47.

26. Oura S, Tamaki T, Hirai I, et al. Radiofrequency ablation therapy in patients with breast cancers two centimeters or less in size. Breast Cancer. 2007;14(1):48-54.

27. Yamamoto N, Fujimoto H, Nakamura R, et al. Pilot study of radiofrequency ablation therapy without surgical excision for $\mathrm{T} 1$ breast cancer: evaluation with MRI and vacuum-assisted core needle biopsy and safety management. Breast Cancer. 2011;18(1):3-9.

28. Seki K, Tsuda H, Iwamoto E, Kinoshita T. Histopathological effect of radiofrequency ablation therapy for primary breast cancer, with special reference to changes in cancer cells and stromal structure and comparison with enzyme histochemistry. Breast Cancer. 2011;18(1):18-23.

29. Tsuda H, Seki K, Hasebe T, et al. A histopathological study for evaluation of therapeutic effects of radiofrequency ablation in patients with breast cancer. Breast Cancer. 2011;18(1):24-32.

30. Berber E, Flesher N, Siperstein A. Initial clinical evaluation of the RITA 5 centimeter radiofrequency thermal ablation catheter in the treatment of liver tumors. Cancer J Sci Am. 2000;6(suppl):319-329.
31. Mirza AN, Fornage BD, Sneige N, et al. Radiofrequency ablation of solid tumors. Cancer J. 2001;7(2):95-102.

32. Singletary SE. Minimally invasive techniques in breast cancer treatment. Semin Surg Oncol. 2001;20(3):246-250.

33. van den Bosch MA, Daniel BL. MR-guided interventions of the breast. Magn Reson Imaging Clin N Am. 2005;13(3):505-517.

34. Organ LW. Electrophysiologic principles of radiofrequency lesion making. Appl Neurophysiol. 1976;39(2):69-76.

35. Scudamore C. Volumetric radiofrequency ablation: technical considerations. Cancer J Sci Am. 2000;6(suppl):316-318.

36. Dickson J, Calderwood S. Thermosensitivity of neoplastic tissues in vivo. In: Storm F, editor. Hyperthermia in Cancer Therapy. Boston: GK Hall Medical; 1983:63-140.

37. Benitez PR, Keisch ME, Vicini F, et al. Five-year results: the initial clinical trial of MammoSite balloon brachytherapy for partial breast irradiation in early-stage breast cancer. Am J Surg. 2007;194(4):456-462.

38. Polgar C, Fodor J, Major T, et al. Breast-conserving treatment with partial or whole breast irradiation for low-risk invasive breast carcinoma - 5-year results of a randomized trial. Int J Radiat Oncol Biol Phys. 2007;69(3):694-702.

39. Morrow M. Current controversies in the local therapy of breast cancer: margins and non surgical ablation. The Proceeding of the 14th Annual Meeting of the Japanese Breast Cancer Society. Kanazawa: 2006:144-145.
OncoTargets and Therapy

\section{Publish your work in this journal}

OncoTargets and Therapy is an international, peer-reviewed, open access journal focusing on the pathological basis of all cancers, potential targets for therapy and treatment protocols employed to improve the management of cancer patients. The journal also focuses on the impact of management programs and new therapeutic agents and protocols on

\section{Dovepress}

patient perspectives such as quality of life, adherence and satisfaction The manuscript management system is completely online and includes a very quick and fair peer-review system, which is all easy to use. Visit http://www.dovepress.com/testimonials.php to read real quotes from published authors. 